\title{
Title: Audiological monitoring in Swiss childhood cancer patients
}

Annette Weiss ${ }^{1}$, Rahel Kuonen ${ }^{1}$, Hanna Brockmeier ${ }^{2}$, Michael Grotzer ${ }^{3}$, Claudia Candreia ${ }^{4}$, Raphael Maire ${ }^{5}$, Pascal Senn ${ }^{6}$, Christof Stieger ${ }^{7}$, Jochen Rosenfeld ${ }^{8}$, Dorothe Veraguth ${ }^{9}$, Martin

Kompis $^{10}$, Katrin Scheinemann ${ }^{11}$, Claudia E. Kuehni ${ }^{1,12}$ for the Swiss Paediatric Oncology Group $(\mathrm{SPOG})^{\mathrm{a}}$.

${ }^{1}$ Swiss Childhood Cancer Registry, Institute of Social and Preventive Medicine, University of Bern, Switzerland.

${ }^{2}$ Clinic for Otolaryngology, Head and Neck Surgery, Kantonspital Aarau, Switzerland

${ }^{3}$ Department of Paediatric Oncology, University Children`s Hospital Zurich, University of

Zurich, Switzerland.

${ }^{4}$ Department of ENT, Head and Neck Surgery, Kantonspital Luzern, Switzerland.

${ }^{5}$ Department of Otorhinolaryngology, Head and Neck Surgery, Lausanne University Hospital, Switzerland.

${ }^{6}$ Department of Clinical Neurosciences, Service for Otorhinolaryngology, Head \& Neck Surgery, University Hospital Geneva, Switzerland.

${ }^{7}$ Department of ENT, University Hospital Basel, Switzerland.

${ }^{8}$ Department of Phoniatrics and Pedaudiology, Cantonal Hospital St Gallen, Switzerland.

${ }^{9}$ Department of Otorhinolaryngology—Head and Neck Surgery, University Hospital Zurich, Switzerland.

${ }^{10}$ Department of ENT, Head and Neck Surgery, University Hospital Bern, University of Bern, Switzerland.

${ }^{11}$ Division of Pediatric Hematology/Oncology, University Children`s Hospital Basel \& University of Basel, Switzerland. 
${ }^{12}$ Children’s University Hospital of Bern, University of Bern, Switzerland.

${ }^{a}$ Swiss Paediatric Oncology Group (SPOG) Scientific Committee: Prof. Dr. med. R. Ammann, Bern; Dr. med. R. Angst, Aarau; Prof. Dr. med. M. Ansari, Geneva; Prof. Dr. med. M. Beck Popovic, Lausanne; PD Dr. med. E. Bergstraesser, Zurich; Dr. med. P. Brazzola, Bellinzona; Dr. med. J. Greiner, St. Gallen; Prof. Dr. med. M. Grotzer, Zurich; Dr. med. H. Hengartner, St. Gallen; Prof. Dr. med. T. Kuehne, Basel; Prof. Dr. med. K. Leibundgut, Bern; Prof. Dr. med. F. Niggli, Zurich; PD Dr. med. J. Rischewski, Lucerne; Prof. Dr. med. N. von der Weid, Basel.

Correspondence to: Claudia E. Kuehni, Prof. MD; Institute of Social and Preventive Medicine, University of Bern, Finkenhubelweg 11, 3012 Bern, Switzerland; E-mail: claudia.kuehni@ispm.unibe.ch; Telephone: +41 3163135 07; Facsimile: +41 316313520

\author{
Abstract word count: 250 \\ Main text word count: 3497 \\ Tables: 4, Figures: 1 \\ Supplemental files: Figures: 2; Tables: 2 \\ Short running title: Audiological monitoring in childhood cancer patients
}

Key words: Ototoxicity, childhood cancer patients, carboplatin, cisplatin, cranial radiation 
Abbreviations:

\begin{tabular}{|l|l|}
\hline AAA & American Academy of Audiology \\
\hline AE & Audiological evaluation \\
\hline ASHA & American Speech-Language-Hearing Association \\
\hline BMT & Bone marrow transplantation \\
\hline COG & Children's Oncology Group \\
\hline CNS & Central nervous system \\
\hline CI & Confidence interval \\
\hline ENT & Ear-nose-throat \\
\hline GPOH & German Society of Paediatric Oncology and Haematology \\
\hline Gy & Gray \\
\hline ICCC-3 & International Classification of Childhood Cancer, Third edition \\
\hline IQR & Interquartile range \\
\hline OAE & Otoacoustic emissions \\
\hline OR & Odds ratio \\
\hline SCCR & Swiss Childhood Cancer Registry \\
\hline SD & Standard deviation \\
\hline SFOP & French Pediatric Oncology Society \\
\hline Std & International Society of Paediatric Oncology \\
\hline
\end{tabular}




\section{ABSTRACT}

2 Background: Full audiological monitoring is the best strategy to detect hearing loss early and

3 to provide timely intervention in the absence of a clinical method of otoprotection. Full

4 monitoring requires audiological evaluation before, and then during and after ototoxic cancer

5 treatment. In a worldwide context of monitoring protocols that vary substantially, we

6 analyzed the audiological monitoring of childhood cancer patients over the last decade across

7 treatment centers in Switzerland.

8 Procedure: We retrospectively searched for audiological evaluations in all nine Swiss

9 Pediatric Oncology Centers. We analyzed proportions of patients who had audiological

monitoring and described type and timing of monitoring. We determined predictors of audiological monitoring using multivariable logistic regression and described time trends.

12 Results: We included 185 patients from the Swiss Childhood Cancer Registry diagnosed 13 2005-2013 who had platinum chemotherapy and/or cranial radiation $\geq 30$ Gray and who were

14 alive at time of study. Less than half of children, 43\%, had full audiological monitoring 15 (before, during, and after treatment), while 72\% were tested after cancer treatment. Non-study 16 patients were less likely to have had monitoring in all phases of cancer treatment. Patients

17 who received treatment with cisplatin or both platinum chemotherapy and cranial radiation

18 were more likely to have had monitoring after treatment. Monitoring during and after

19 treatment increased over the study period, but monitoring before treatment was insufficient in 20 all time periods.

21 Conclusions: Our population-based study indicates that audiological monitoring is

22 insufficient in Switzerland, particularly for non-study patients. Clinicians' must become more 23 aware of the importance of full audiological monitoring. 


\section{INTRODUCTION}

Platinum chemotherapy or/and cranial radiation can be toxic to the ear, a property called ototoxicity. ${ }^{1-3}$ Platinum can cause sensorineural hearing loss due to toxic levels of reactive oxygen species in the cochlea that damage hair cells, the stria vascularis, and spiral ganglion cells. ${ }^{1}$ Radiation $\geq 30$ Gray (Gy) can cause sensorineural or conductive hearing loss due to direct damage to the external ear canal, the cochlea, the brainstem, or small vessels of the inner ear. ${ }^{1}$ High-frequency hearing loss is most common and may progress unnoticed until communication problems become apparent. ${ }^{1,4}$ In children, moderate or even rather minimal hearing loss can impair speech development, cause learning problems, or reduce quality of life..$^{5-9}$ It is, therefore, crucial that hearing loss is detected early. Clinicians might have the option to discuss whether cancer treatment can be modified, they can counsel patients and parents, offer hearing aids and thus mitigate the downstream effects of hearing loss. International guidelines ${ }^{10-14}$ and clinical studies (Supplementary Table S1) recommend audiological monitoring because no clinical method of otoprotection yet exists. ${ }^{15}$ Both the number of evaluations recommended and their timing vary substantially. However, all agree that full monitoring includes an initial audiological evaluation at baseline, before ototoxic treatment, to exclude any pre-existing hearing disorder; that evaluations should be repeated throughout the ototoxic treatment so that clinicians may modify cancer treatment; and that evaluation should continue after completion of cancer treatment to detect potential latemanifesting hearing loss. Patients receiving only cranial radiation should be evaluated both before and after radiation of $\geq 30$ Gy. However, no study has yet investigated whether clinicians adhere to these recommendations, and whether patient characteristics or cancer treatment predict monitoring, or if participation in a clinical study plays a role in monitoring. We characterized audiological monitoring in a national, registry-based sample of childhood cancer patients who received ototoxic cancer treatment. We analyzed predictors of 
49 audiological monitoring and evaluated whether audiological monitoring improved over the 50 last decade. 


\section{METHODS}

\section{Study population}

The Swiss Childhood Cancer Registry (SCCR) is a nationwide, population-based registry that includes all children and adolescents residing in Switzerland who have been diagnosed with leukemia, lymphoma, central nervous system (CNS) tumors, malignant solid tumors, or Langerhans cell histiocytosis prior to the age of $21 .{ }^{16}$ Recent estimates indicate that the SCCR includes $91 \%$ of all patients diagnosed with cancer before the age of 16 in the years since 1985, and about $95 \%$ of those diagnosed since $1995 .{ }^{17}$ The SCCR registers information on the diagnosis and treatment of the cancer and personal information. Tumors are classified according to the International Classification of Childhood Cancer, third edition (ICCC-3). ${ }^{18}$ Ethics approval of analyses of SCCR data is granted by the Ethics Committee of the Canton of Bern to the SCCR (KEK-BE: 166/2014).

\section{Inclusion criteria}

We included all patients registered in the SCCR who were treated with ototoxic cancer treatment in the nine Swiss Pediatric Oncology Centers (Supplementary Fig. S1). We restricted the years of diagnosis to 2005-2013 because medical records from patients treated before 2005 are difficult to access due to Swiss data protection rules, ${ }^{19}$ and the treatment and follow-up of patients diagnosed after 2013 was not finished when data collection ended in December 2015. We assumed that audiological monitoring may not have been the first priority in treating terminally ill children, and excluded the records of children who were not alive at the time of study; in any event, their medical records were often not available. ${ }^{19}$ We defined ototoxic cancer treatment as platinum chemotherapy or cranial radiation $\geq 30$ Gy according to the literature. ${ }^{11,13,14,20,21}$ To determine whether patients fulfilled the inclusion criteria, we obtained their personal and treatment-related information from the SCCR. 


\section{Chart review}

We reviewed the medical records retrospectively. We collected audiological tests, the corresponding audiologists' reports, oncological discharge reports, and cancer treatment protocols in all nine Swiss Pediatric Oncology Centers and the corresponding ear-nose-throat departments.

\section{Audiological monitoring}

Through the end of 2015, we collected all audiological tests that were performed as part of care before, during, and after cancer treatment, and recorded the type and timing of evaluation. We categorized type of audiological test as pure tone audiometry, extended high frequency audiometry, free field audiometry, auditory brainstem response, otoacoustic emissions (OAE) testing, speech audiometry, or tympanometry. To assess the timing of audiological evaluation, we categorized tests as before, during, and after treatment. We divided the extent of audiological monitoring into two categories: i) full audiological monitoring included patients with at least one evaluation at all stages (before, during, and after cancer treatment); and ii) minimal audiological monitoring included patients with one or more evaluation that occurred only after treatment. Patients with cranial radiation were defined as having had full audiological monitoring if they received at least one evaluation preand post-treatment. We graded the most recent hearing test for each ear separately and for frequencies up to $8 \mathrm{kHz}$ according to the SIOP Boston Ototoxicity Scale, which is more sensitive to detect hearing loss than other ototoxicity scales. ${ }^{22,23}$ We defined hearing loss as $\geq$ grade 1 ( $>20 \mathrm{~dB}$ above $4 \mathrm{kHz}$ ) according to the SIOP Boston Ototoxicity scale in the most affected ear, and graded severity from 0 to $4 .^{22}$

\section{Cancer treatment information}

We collected detailed patient information on cancer treatment from the SCCR, or from the clinic archives when it was not available in the SCCR. We recorded the name and arm of the 
101 clinical study, if applicable, the start and end dates of ototoxic cancer treatment, and dose of

102 platinum chemotherapy or cranial radiation. We divided patients into three clinical study

103 participation groups: patients officially registered in a clinical study; patients not registered in

104 but treated according to a clinical study protocol (e.g., closed clinical study, study not open at

105 the clinic); and patients who were treated but were neither registered in nor treated according

106 to a study protocol. We classified patients into three ototoxic cancer treatment groups: cranial

107 radiation $\geq 30 \mathrm{~Gy}$, carboplatin, cisplatin, or both platinum chemotherapy and cranial radiation

$108 \geq 30 \mathrm{~Gy}$.

109 Statistical analysis

110 We first determined how many children had had at least one audiological evaluation

111 overall, and at least one evaluation before, during, or after cancer treatment. To investigate

112 whether audiological monitoring varies between subgroups, we stratified for age at cancer

113 diagnosis, ototoxic cancer treatment, clinical study participation, and hearing status at the last

114 audiological evaluation. We then characterized the types of audiological tests used before,

115 during, and after treatment, overall and stratified for age at cancer diagnosis. In a third step,

116 we determined the number of evaluations patients had among those who received any

117 monitoring, and described the length of audiological follow-up after ototoxic cancer

118 treatment. We only considered patients with $\geq 5$ years between last ototoxic treatment and

119 time of study to have similar chances to be monitored among patients. The fourth step

120 assessed predictors of audiological monitoring by using logistic regression models. We first

121 compared patients who had full audiological monitoring to all who did not have full

122 audiological monitoring, and then compared patients who had minimal audiological

123 monitoring to those without any audiological monitoring. We used gender, age at cancer

124 diagnosis, ototoxic cancer treatment, and clinical study participation as independent variables.

125 Finally, we assessed time trends in audiological monitoring. We compared proportions of 
126 children who received audiological monitoring before, during, and after treatment between

127 periods of cancer diagnosis, and tested for trends. To treat post-treatment differences with

128 different lengths of follow-up equally, we considered only audiological evaluations within the

129 first year after ototoxic treatment. We also used the Kaplan-Meier method to estimate

130 cumulative incidence curves and calculated cumulative incidence for audiological monitoring

13112 months after treatment stratified by period of diagnosis.

132 We used Stata (Version 13, Stata Corporation, Austin, Texas) for all analyses. 
RESULTS

\section{Characteristics of study population}

135 Among 1,916 children diagnosed 2005-2013 with cancer, 306 had potentially ototoxic

136 treatment and of these 210 were alive and eligible for the study. The medical records of 14

137 children were missing, and we excluded another 11 children who had been treated in

138 Bellinzona, where both cancer care and follow-up are often shared with larger clinics and

139 assessment of the complete medical records for a patient was not feasible. This resulted in 185

140 patients whose records were available for analysis (Supplementary Fig. S1, Table 1). The

141 mean age (SD) of these patients was 7 (5) years at diagnosis and 11 (6) years at the most

142 recent audiological evaluation. Table 1 gives details on clinical characteristics and cancer

143 treatment of the study population. Fifty-six patients (30\%) had a pathological result in the

144 most recent audiological evaluation, among whom 25 patients (13\%) had severity grade 1,

145 while 21 patients (11\%) had grade 2, 7 patients (4\%) had grade 3, and 3 patients (2\%) had

146 grade 4.

147 Proportion tested, and type of audiological tests

148 Overall, 175 children (95\%) treated with ototoxic cancer treatment had at least one

149 evaluation, but only 78 children (42\%) had full audiological monitoring in all phases of

150 cancer treatment. Looking at each phase separately, 122 patients (66\%) had at least one test

151 before treatment, 125 (74\%) were tested at least once during treatment, and 134 (72\%) were

152 tested one or more times after treatment (Table 2). Evaluation before treatment was more

153 common in patients who were included in a clinical study or were treated according to a study

154 protocol than in those whose treatment was not part of or conducted according to a study

155 (73\% and 64\% respectively vs. 35\%). Evaluation during treatment was less common in those

156 younger than 5 years at diagnosis (60\%), in those with carboplatin (61\%), and in non-study

157 patients (21\%); and more common in patients older than 9 years at diagnosis (89\%), in those 
with cisplatin (81\%) or with both platinum chemotherapy and cranial radiation $\geq 30$ Gy $(77 \%)$, or in those officially included in a clinical study (82\%). Evaluation after treatment was less common in patients with cranial radiation $\geq 30 \mathrm{~Gy}(56 \%)$, in those with carboplatin (51\%), or in non-study patients (24\%), but more common in those with cisplatin (85\%) or both platinum chemotherapy and cranial radiation $\geq 30$ Gy $(81 \%)$.

Pure tone audiometry, extended high frequency audiometry, and OAE testing were the most frequently used types of tests, independent of the time of treatment (Supplementary Table S2).

\section{Frequency of audiological evaluations and follow-up period}

Patients had in median one evaluation before, three during, or two after treatment (Table 3). During treatment, tests were more frequent in patients with both platinum chemotherapy and cranial radiation $\geq 30$ Gy $(\mathrm{P}<0.001)$. After treatment, tests were done more often in patients older than 9 years at diagnosis $(\mathrm{P}=0.020)$, in study patients $(\mathrm{P}=0.036)$ and in those who have developed hearing loss $(\mathrm{P}<0.001)$. Patients who received ototoxic cancer treatment five or more years ago had a median audiological follow-up of 29 months. The longest follow-up had those who received cranial radiation of $\geq 30$ Gy (median 56 months, $\mathrm{P}=0.013$ ).

\section{Predictors for full and minimal audiological monitoring}

Full audiological monitoring differed with clinical study participation (Table 4). Full monitoring was less common in non-study patients (adjusted OR 0.1). Only one out of 17 children not treated according to a clinical study had full audiological monitoring. Minimal audiological monitoring differed with ototoxic cancer treatment and clinical study participation. It was more common in patients with cisplatin or both platinum chemotherapy and cranial radiation $\geq 30$ Gy (adjusted OR 2.5, 1.5, respectively) and less common in nonstudy patients (adjusted OR 0.2). Only four out of 17 children not treated according to a clinical study had minimal audiological monitoring. 


\section{Time trends of audiological monitoring}

184 Proportions of patients with audiological monitoring changed over the last decade (Fig. 1).

185 In 2005-2006, 55\% had at least one evaluation before treatment. That proportion increased to

$18679 \%$ in 2009-2010, but decreased back to baseline in 2013 (50\%, P-trend=0.912). The

187 proportion of patients with at least one evaluation during treatment increased from $68 \%$ in

$1882005-2006$ to $88 \%$ in 2013 (P-trend=0.045), and the proportion with at least one evaluation 12

189 months after treatment increased from 42\% in 2005-2006 to 60\% in 2013 (P-trend=0.066).

190 We found a nonsignificant trend towards an increasing cumulative incidence of auditory

191 monitoring 12 months after treatment $(\mathrm{P}=0.059$, Supplementary Fig. S2). Cumulative

192 incidence of first audiological evaluation within 12 months after treatment was 45\% (95\% CI

193 31-62\%) in those diagnosed 2005-2006, 52\% (95\% CI 38-68\%) in those diagnosed 2007-

194 2008, 60\% (95\% CI 45-74\%) in those diagnosed 2009-2010, and 65\% (95\% CI 51-79\%) in

195 those diagnosed 2011-2012. Periods of diagnosis did not differ in age at diagnosis $(\mathrm{P}=0.666)$

196 or ototoxic cancer treatment $(\mathrm{P}=0.788)$. 


\section{DISCUSSION}

198

This study of Swiss childhood cancer patients found that less than half of the children had full audiological monitoring that included an evaluation before, during, and after ototoxic cancer treatment. Seventy-two percent of study patients did receive at least one audiological evaluation after treatment, but non-study patients had significantly less audiological monitoring. Though monitoring during and after ototoxic treatment has become more frequent over the last decade, monitoring before treatment has been and remains insufficient.

$$
\text { Evaluations before treatment provide a crucial reference for assessing hearing changes, and }
$$
are needed for ototoxicity grading scales. ${ }^{10,12,24-26}$ They should therefore be as comprehensive as possible to have reference values for any evaluation conducted after ototoxic treatment. Yet in our study only 31 of 53 children (58\%) at high risk to develop hearing loss from ototoxic therapy with platinum chemotherapy and cranial radiation had been monitored before treatment. Monitoring rates for baseline testing have been reported in other studies. Among seven oncologists and 16 audiologists in New Zealand who were interviewed to assess their knowledge of audiological monitoring of patients receiving potentially ototoxic treatment, all of the audiologists and six of the seven oncologists rated baseline evaluation as important. ${ }^{27}$ Yet the clinicians had limited familiarity with guidelines, and their clinical practices varied, ranging from no routine monitoring to evaluations prior to each cycle of chemotherapy. A retrospective study in the U.S. found that hearing tests were performed at baseline in $71 \%$ of children with retinoblastoma treated under a Children’s Hospital of Philadelphia protocol. ${ }^{28}$ However, in a study of children under the age of 18 who were treated for solid tumors with cisplatin and/or carboplatin according to SFOP protocols between 1987 and 1997 at the institute Gustave-Roussy in France, a low proportion of patients, 34 of 120 (28\%), received an audiometric evaluation prior to the first course of treatment. ${ }^{29}$ These reports, as well as the 
paucity of such studies in the literature, reinforce our observation that evaluation before

222 treatment falls well short of the need for it.

223 Monitoring during treatment is specified by treatment protocols that have different

224 monitoring schedules (Supplementary Table S1). For example, the Euramos protocol for

225 osteosarcoma treatment used in 31 children in our study population suggested that only an

226 evaluation before the $3^{\text {rd }}$ and $4^{\text {th }}$ cycle of cisplatin is needed. But, for 31 children treated

227 according to HIT-2000, a protocol used to treat medulloblastoma, CNS PNET or

228 ependymoma, monitoring was advised at each cycle of platinum chemotherapy. The protocol

229 used to treat 10 children with medulloblastoma, ACNS0331, specified monitoring prior to

230 every cisplatin cycle, which is in line with both American Academy of Audiology (AAA) and

231 American Speech-Language-Hearing Association (ASHA) recommendations. ${ }^{10,12}$ Overall,

$23274 \%$ of our patients had at least one test during treatment. The percentage rose to $89 \%$ among

233 patients who were older than 9 years, while $81 \%$ of those treated with cisplatin and $77 \%$ of

234 those treated with both platinum chemotherapy and cranial radiation were tested at least once,

235 as were $82 \%$ of those included in a clinical study.

236 After ototoxic treatment, the St. Jude Children's research hospital protocol recommends

237 yearly evaluation up to 10 years after cancer treatment (Supplementary Table S1). ${ }^{30}$ However,

238 the Children’s Oncology Group Long-Term Follow-Up Guidelines recommend monitoring

239 only if impairment is detected after treatment. ${ }^{11}$ Variation across guidelines is by itself

240 unlikely to explain why $28 \%$ of our patients received no evaluation after treatment.

241 Participation in or treatment according to a clinical study improves monitoring. Thirteen of

242 the 17 non-study patients received no post-treatment monitoring. Of these 17 non-study

243 patients, 12 were diagnosed before the age of 5, 13 were diagnosed with retinoblastoma, and

24412 were treated solely with carboplatin. In Switzerland, institutional treatment protocols do

245 not specify standardized protocols for audiological monitoring for retinoblastoma patients, 
and because carboplatin is less ototoxic clinicians may have performed fewer evaluations in this group. ${ }^{1,3}$ However, international guidelines do not exclude children treated only with carboplatin, and particularly for patients with retinoblastoma development of an additional sensory handicap is crucial. ${ }^{31,32}$ But conducting audiometry is challenging in this age group.

Especially when young children are seriously ill, their cooperation and attention may be

251 reduced, which can lead to hearing test results that have poor reliability, and to overall low

252 testing rates. ${ }^{22}$ In all cases, though, audiological monitoring for several years after cancer

253 treatment is important as hearing loss may only appear many years later particularly for

254 patients treated with cranial radiation. ${ }^{3,33}$

255 Guidelines for audiological monitoring have changed over time. The 1994 ASHA

256 guideline reported ototoxic effects only for platinum chemotherapy; audiological effects of

257 cranial radiation were not well known at that time. ${ }^{10,34}$ Fifteen years later, the AAA guideline

258 recommended annual monitoring for one to two years after cranial radiation. ${ }^{12}$ Independent of

259 monitoring schedules, evaluations themselves may be adjusted by, for example, focusing on

260 the high frequencies that are critical in determining the onset of hearing loss. ${ }^{24}$ In the current

261 St. Jude Children’s Hospital ototoxicity protocol, the number of evaluations depends on the

262 platinum compound used or the dose of cranial radiation, but at least eleven hearing tests are

263 recommended. ${ }^{30}$ It is therefore no surprise that audiological monitoring during and after

264 treatment has increased since 2005, though monitoring before treatment has not.

265 Our study was restricted to a retrospective review of charts from the clinics in which

266 patients were treated for cancer. If any post-treatment evaluations were done in private

267 practice our search would have missed them. To reduce this potential bias, we excluded

268 patients treated in Bellinzona, a small clinic where identification of all medical documents

269 was not feasible. With different guidelines recommending different numbers and timing of

270 audiological evaluations, we simplified our definition of full audiological monitoring to 
271

272

273

274

275

276

encompass only a single evaluation at each treatment stage. We may have overestimated the adherence to monitoring guidelines, because we had no information on the indication for every audiological evaluation. Testings may have been done for indications other than ototoxicity monitoring (e.g. repeated ear infections). Another reason for an overestimation could be that childhood cancer patients who developed hearing loss may have received audiological evaluation not only for detection, but also for follow-up of hearing loss. We also did not have detailed information on type of radiation. Patients irradiated with protons thus may have received a lower dose to the auditory system and be at lower risk of developing hearing loss than those who had photon radiation therapy. Hearing loss can also occur after radiation with doses $<30 \mathrm{~Gy}$, but we only included patients who received cranial radiation $\geq 30$

Gy in the study population. Several studies suggest the cut-off of 30 Gy for ototoxicity. ${ }^{11,20,21}$ We, therefore, expected clinicians to adhere to audiological monitoring guidelines only for those patients. Finally, our results cannot be extrapolated to children who died after cancer diagnosis.

Our study does have several strengths. Using unique data from medical records to investigate audiological monitoring, we were able to include patients with different childhood cancer diagnoses and different treatment protocols. Having exact dates of ototoxic exposure and audiological evaluations enabled us to analyze the timing of monitoring in detail. We also considered children diagnosed 2005-2013, which allowed us to evaluate changes over time.

Our results highlight how important it is to increase clinicians' compliance with audiological monitoring guidelines. We suggest clinicians comply with either recommendations of clinical studies or more general recommendations like the ASHA guideline, especially for non-study patients in the absence of a study protocol for audiological monitoring. We believe that compliance with audiological monitoring recommendations would increase if different clinical studies and guidelines harmonize numbers and timing of 
audiological evaluations. The International Late Effects of Childhood Cancer Guideline

297 Harmonization Group (www.ighg.org) is currently developing recommendations for

298 ototoxicity monitoring after cancer treatment to unify existing recommendations and to

299 provide optimum follow-up practices for audiological monitoring. This new guideline based

300 on current literature, follow-up guidelines, and expert consensus will define who needs

301 audiological monitoring, at what frequency, for how long, and what modality should be used.

302 In summary, our study indicates that audiological monitoring guidelines are insufficiently

303 followed in Switzerland, particularly when patients are neither participants in a study nor

304 treated according to a specific study protocol. We need to increase clinicians' knowledge of

305 the importance of full audiological monitoring before, during, and after cancer treatment to

306 increase compliance with international monitoring guidelines. Pediatric oncologists should be

307 made aware of the need to send childhood cancer patients who will receive potentially

308 ototoxic treatment to an audiologist for pretreatment monitoring. Standardized audiological

309 monitoring that begins with a baseline evaluation is essential for the best possible audiological

310 outcomes. 
The commercial funders of the Swiss Childhood Cancer Registry support the daily operation of the registry, but have not had nor will have any role in the design, conduct, or

314 interpretation of any research project and related publications based upon the Swiss

315 Childhood Cancer Registry.

\section{ACKNOWLEDGEMENTS}

317 We thank the data managers of the Swiss Paediatric Oncology Group (Claudia Anderegg, 318 Pamela Balestra, Nadine Beusch, Rosa-Emma Garcia, Franziska Hochreutener, Friedgard 319 Julmy, Nadia Lanz, Rodolfo Lo Piccolo, Heike Markiewicz, Annette Reinberg, Renate 320 Siegenthaler, Verena Stahel), and the team of the Swiss Childhood Cancer Registry (Verena 321 Pfeiffer, Katharina Flandera, Shelagh Redmond, Meltem Altun, Parvinder Singh). Further, we 322 thank the teams of the ENT-departments (Marie-Madeleine Knuchel, Cecile Moreno, Julia 323 Bernath, Sandra Schenk) and Gierin Thomi, Marie Bulliard, Annette Schneeberger, and Laura 324 Caramanica for their help in collecting audiological and treatment data from medical records. 325 We thank Christopher Ritter for his editorial suggestions.

326 This study was supported by the Swiss Cancer Research (grant no: 02783-02-2011), Swiss 327 Cancer League (grant no: 3412-02-2014), and received funding from the European Union’s 328 Seventh Framework Programme for research, technological development and demonstration 329 under grant agreement no 602030.

330 The work of the Swiss Childhood Cancer Registry is supported by the Swiss Paediatric 331 Oncology Group (www.spog.ch), Schweizerische Konferenz der kantonalen

332 Gesundheitsdirektorinnen und -direktoren (www.gdk-cds.ch), Swiss Cancer Research 333 (www.krebsforschung.ch), Kinderkrebshilfe Schweiz (www.kinderkrebshilfe.ch), the Federal 
334 Office of Health (FOPH) and the Institute of Cancer Epidemiology and Registration 335 (www.nicer.org). 
337 1. Landier W. Ototoxicity and cancer therapy. Cancer 2016; 122(11): 1647-58.

338 2. van As JW, van den Berg H, van Dalen EC. Platinum-induced hearing loss after

339 treatment for childhood cancer. Cochrane Database Syst Rev 2016(8): Cd010181.

340 3. Weiss A, Sommer G, Kasteler R, Scheinemann K, Grotzer M, Kompis M, Kuehni CE, cancer: A report from the Swiss Childhood Cancer Survivor Study. Pediatr Blood Cancer 2017; 64(2): 364-373.

4. Berg AL, Spitzer JB, Garvin JH, Jr. Ototoxic impact of cisplatin in pediatric oncology patients. Laryngoscope 1999; 109(11): 1806-14.

5. Gurney JG, Tersak JM, Ness KK, Landier W, Matthay KK, Schmidt ML, Children's Oncology G. Hearing loss, quality of life, and academic problems in long-term neuroblastoma survivors: a report from the Children's Oncology Group. Pediatrics 2007; 120(5): e1229-36.

6. Knight KR, Kraemer DF, Neuwelt EA. Ototoxicity in children receiving platinum chemotherapy: underestimating a commonly occurring toxicity that may influence academic and social development. J Clin Oncol 2005; 23(34): 8588-96.

7. Lieu JE, Tye-Murray N, Karzon RK, Piccirillo JF. Unilateral hearing loss is associated with worse speech-language scores in children. Pediatrics 2010; 125(6): e1348-55.

8. Orgel E, O'Neil SH, Kayser K, Smith B, Softley TL, Sherman-Bien S, Counts PA, Murphy D, Dhall G, Freyer DR. Effect of Sensorineural Hearing Loss on Neurocognitive Functioning in Pediatric Brain Tumor Survivors. Pediatr Blood Cancer 2016; 63(3): 527-34.

9. Bess FH, Dodd-Murphy J, Parker RA. Children with minimal sensorineural hearing loss: prevalence, educational performance, and functional status. Ear Hear 1998; 19(5): 339-54.

10. American Speech-Language-Hearing Association. Audiologic management of individuals receiving cochleotoxic drug therapy 1994; Available from:

www.asha.org/policy.

11. Children's Oncology Group. Long-Term Follow-Up Guidelines for Survivors of Childhood, Adolescent and Young Adult Cancers, Version 4.0. 2013; Available from: www.survivorshipguidelines.org.

12. American Academy of Audiology. American Academy of Audiology Position Statement and Clinical Practice Guidelines: Ototoxity Monitoring. 2009; Available from: https://audiologyweb.s3.amazonaws.com/migrated/OtoMonGuidelines.pdf_539974c40999c1.58842217 .pdf.

13. Dutch Childhood Oncology Group. Guidelines for follow-up in survivors of childhood cancer 5 years after diagnosis. 2010; Available from: https://www.skion.nl/workspace/uploads/vertaling-richtlijn-LATER-versie-final-okt2014_2.pdf.

14. United Kingdom Children`s Cancer Study Late Effects Group. Therapy Based Long Term Follow Up - Practice Statement. 2011; Available from: https://www.uhb.nhs.uk/Downloads/pdf/CancerPbTherapyBasedLongTermFollowUp. pdf.

15. van As JW, van den Berg H, van Dalen EC. Medical interventions for the prevention of platinum-induced hearing loss in children with cancer. Cochrane Database Syst Rev 2016; 9: Cd009219. 
16. Michel G, von der Weid NX, Zwahlen M, Adam M, Rebholz CE, Kuehni CE, Swiss Childhood Cancer Registry, Swiss Paediatric Oncology Group Scientific Committee. The Swiss Childhood Cancer Registry: rationale, organisation and results for the years 2001-2005. Swiss Med Wkly 2007; 137(35-36): 502-9.

17. Schindler M, Mitter V, Bergstraesser E, Gumy-Pause F, Michel G, Kuehni CE. Death certificate notifications in the Swiss Childhood Cancer Registry: assessing completeness and registration procedures. Swiss Med Wkly 2015; 145: w14225.

18. Steliarova-Foucher E, Stiller C, Lacour B, Kaatsch P. International Classification of Childhood Cancer, third edition. Cancer 2005; 103(7): 1457-67.

19. Eidgenössischer Datenschutz- und Öffentlichkeitsbeauftragter (EDÖB). Leitfaden für die Bearbeitung von Personendaten im medizinischen Bereich. 2002; Available from: https://www.edoeb.admin.ch/datenschutz/00628/00629/00635/index.html?lang=de.

20. Hua C, Bass JK, Khan R, Kun LE, Merchant TE. Hearing loss after radiotherapy for pediatric brain tumors: effect of cochlear dose. Int J Radiat Oncol Biol Phys 2008; 72(3): 892-9.

21. Merchant TE, Gould CJ, Xiong X, Robbins N, Zhu J, Pritchard DL, Khan R, Heideman RL, Krasin MJ, Kun LE. Early neuro-otologic effects of three-dimensional irradiation in children with primary brain tumors. Int J Radiat Oncol Biol Phys 2004; 58(4): 1194-207.

22. Brock PR, Knight KR, Freyer DR, Campbell KC, Steyger PS, Blakley BW, Rassekh SR, Chang KW, Fligor BJ, Rajput K, Sullivan M, Neuwelt EA. Platinum-induced ototoxicity in children: a consensus review on mechanisms, predisposition, and protection, including a new International Society of Pediatric Oncology Boston ototoxicity scale. J Clin Oncol 2012; 30(19): 2408-17.

23. Knight KR, Chen L, Freyer D, Aplenc R, Bancroft M, Bliss B, Dang H, Gillmeister B, Hendershot E, Kraemer DF, Lindenfeld L, Meza J, Neuwelt EA, Pollock BH, Sung L. Group-Wide, Prospective Study of Ototoxicity Assessment in Children Receiving Cisplatin Chemotherapy (ACCL05C1): A Report From the Children's Oncology Group. J Clin Oncol 2017; 35(4): 440-445.

24. Bass JK, Bhagat SP. Challenges in ototoxicity monitoring in the pediatric oncology population. J Am Acad Audiol 2014; 25(8): 760-74; quiz 782-3.

25. Fouladi M, Chintagumpala M, Ashley D, Kellie S, Gururangan S, Hassall T, Gronewold L, Stewart CF, Wallace D, Broniscer A, Hale GA, Kasow KA, Merchant TE, Morris B, Krasin M, Kun LE, Boyett JM, Gajjar A. Amifostine protects against cisplatin-induced ototoxicity in children with average-risk medulloblastoma. J Clin Oncol 2008; 26(22): 3749-55.

26. US Department of Health, Human Services, National Institutes of Health, National Cancer Institute. Common Terminology Criteria for Adverse Events (CTCAE) Version 4.0. 2010; Available from: https://ctep.cancer.gov/protocolDevelopment/electronic_applications/ctc.htm.

27. Steffens L, Venter K, O'Beirne GA, Kelly-Campbell R, Gibbs D, Bird P. The current state of ototoxicity monitoring in New Zealand. N Z Med J 2014; 127(1398): 84-97.

28. Lambert MP, Shields C, Meadows AT. A retrospective review of hearing in children with retinoblastoma treated with carboplatin-based chemotherapy. Pediatr Blood Cancer 2008; 50(2): 223-6.

29. Bertolini P, Lassalle M, Mercier G, Raquin MA, Izzi G, Corradini N, Hartmann O. Platinum compound-related ototoxicity in children: long-term follow-up reveals continuous worsening of hearing loss. J Pediatr Hematol Onc 2004; 26(10): 649-55. 
30. Bass JK, White ST, Jones SE. Monitoring Ototoxicity in the Pediatric Oncology Population. 2013; Available from: http://www.asha.org/Articles/Monitoring-

31. Bhagat SP, Bass JK, White ST, Qaddoumi I, Wilson MW, Wu J, Rodriguez-Galindo C. Monitoring carboplatin ototoxicity with distortion-product otoacoustic emissions in children with retinoblastoma. Int J Pediatr Otorhinolaryngol 2010; 74(10): 1156-63.

32. Jehanne M, Lumbroso-Le Rouic L, Savignoni A, Aerts I, Mercier G, Bours D, Desjardins L, Doz F. Analysis of ototoxicity in young children receiving carboplatin in the context of conservative management of unilateral or bilateral retinoblastoma. Pediatr Blood Cancer 2009; 52(5): 637-43.

33. Whelan K, Stratton K, Kawashima T, Leisenring W, Hayashi S, Waterbor J, Blatt J, Sklar CA, Packer R, Mitby P, Robison LL, Mertens AC. Auditory complications in childhood cancer survivors: a report from the childhood cancer survivor study. Pediatr Blood Cancer 2011; 57(1): 126-34.

34. Paulino AC, Simon JH, Zhen W, Wen BC. Long-term effects in children treated with radiotherapy for head and neck rhabdomyosarcoma. Int J Radiat Oncol Biol Phys 2000; 48(5): 1489-95. 


\section{LEGENDS}

451 Table 1 Characteristics of the study population.

452 Table 2 Proportion of patients with audiological monitoring before, during and after ototoxic 453 cancer treatment.

454 Table 3 Frequency of audiological evaluations per patient (including only patients with at 455 least one audiological evaluation).

456 Table 4 Predictors of audiological monitoring in childhood cancer patients.

457 Figure 1 Time trends in the proportion of childhood cancer patients with audiological

458 monitoring.

$459 *$ *P-values derived from chi-square test for trend;

$460 \wedge$ We included only audiological evaluations within the first year after ototoxic cancer 461 treatment.

462 Supplemenatry Table S1 Recommendations for audiological monitoring.

463 Supplemenatry Table S2 Type of audiological tests stratified by phase of ototoxic cancer 464 treatment.

465 Supplemenatry Figure S1 Flow chart of study population.

466 a Including the following clinics: Kinderklinik Kantonsspital Aarau AG, Universitäts467 Kinderspital Basel, Universitäts-Kinderklinik Inselspital Bern, Ospedale S. Giovanni 468 Bellinzona, Hospital des Enfants Geneve, CHUV Lausanne, Kinderklinik Kantonsspital 469 Luzern, Ostschweizer Kinderspital St. Gallen, Universitäts-Kinderspital Zürich 470 ' Ototoxic cancer treatment defined as platinum chemotherapy or and cranial radiation $\geq 30$ 471 Gray.

472 Supplemenatry Figure S2 Cumulative incidence of first audiological evaluation after 473 treatment.

$474 \quad$ P-value derived from log-rank test to test for equivalence of incidence curves.

475 We did not include patients diagnosed in 2013 as for some of those patients the period 476 between the last ototoxic cancer treatment and the data collection was less than 12 months. 


\begin{tabular}{|c|c|}
\hline & $\mathrm{N}=185(\%)$ \\
\hline \multicolumn{2}{|l|}{ Gender } \\
\hline Female & $92(50)$ \\
\hline Male & $93(50)$ \\
\hline \multicolumn{2}{|l|}{ Age at cancer diagnosis } \\
\hline$<5$ year & 73 (39) \\
\hline 5-9 years & $41(22)$ \\
\hline $10-16$ years & $71(38)$ \\
\hline \multicolumn{2}{|l|}{ Period of cancer diagnosis } \\
\hline $2005-2006$ & $38(21)$ \\
\hline 2007-2008 & $42(23)$ \\
\hline $2009-2010$ & $42(23)$ \\
\hline 2011-2012 & $43(23)$ \\
\hline 2013 & $20(11)$ \\
\hline \multicolumn{2}{|l|}{ Cancer diagnosis (ICCC-3) } \\
\hline III: CNS tumor & 72 (39) \\
\hline IV: Neuroblastoma & $16(9)$ \\
\hline V: Retinoblastoma & $17(9)$ \\
\hline VI: Renal tumor & $7(4)$ \\
\hline VII: Hepatic tumor & $5(3)$ \\
\hline VIII: Bone tumor & 35 (19) \\
\hline IX: Soft tissue sarcoma & $11(6)$ \\
\hline $\mathrm{X}$ : Germ cell tumor & $22(11)$ \\
\hline \multicolumn{2}{|l|}{ Localisation } \\
\hline Supratentorial & $25(14)$ \\
\hline Infratentorial & $42(23)$ \\
\hline Extracranial & 25 (14) \\
\hline Intraspinal & $13(7)$ \\
\hline Others, not head & $80(43)$ \\
\hline \multicolumn{2}{|l|}{ Type of clinical study ${ }^{\mathrm{a}}$} \\
\hline SIOP & $64(35)$ \\
\hline GPOH \& SFOP & $75(41)$ \\
\hline COG & $50(27)$ \\
\hline \multicolumn{2}{|l|}{ Clinical study participation } \\
\hline Officially included in a clinical study & $93(50)$ \\
\hline Treated according to a clinical study & $75(41)$ \\
\hline Treated not according to a clinical study & $17(9)$ \\
\hline \multicolumn{2}{|l|}{ Platinum chemotherapy } \\
\hline Cisplatin & $98(53)$ \\
\hline Mean (SD, range) dose in $\mathrm{mg} / \mathrm{m}^{2}$ & $388(141,30-800)$ \\
\hline Carboplatin & $92(50)$ \\
\hline Mean $\left(S D\right.$, range) dose in $\mathrm{mg} / \mathrm{m}^{2}$ & $3,072(2,874,400-18,661)$ \\
\hline Cranial radiation & $69(37)$ \\
\hline Mean (SD, range) dose in Gy & $56(8,40-77)$ \\
\hline Brain surgery & $65(35)$ \\
\hline \multicolumn{2}{|l|}{ Bone marrow transplantation } \\
\hline No & $171(81)$ \\
\hline Yes & $14(11)$ \\
\hline
\end{tabular}

Abbreviations: ICCC-3, International Classification of Childhood Cancer, Third edition; Gy, Gray; SIOP, International Society of Paediatric Oncology; COG, Children`s Oncology Group; 
GPOH, German Society of Paediatric Oncology and Haematology; SFOP, French Pediatric Oncology Society; SD, standard deviation.

${ }^{a}$ Categories are not exclusive of each other: e.g., Euramos is included in COG and GPOH \& SFOP. 
TABLE 2 Proportion of patients with audiological monitoring before, during and after ototoxic cancer treatment

\begin{tabular}{|c|c|c|c|c|c|c|c|c|c|}
\hline & \multicolumn{3}{|c|}{$\begin{array}{c}\text { Before treatment } \\
(\mathrm{n}=185)\end{array}$} & \multicolumn{3}{|c|}{$\begin{array}{l}\text { During treatment }{ }^{\mathrm{a}} \\
(\mathrm{n}=169)\end{array}$} & \multicolumn{3}{|c|}{$\begin{array}{l}\text { After treatment } \\
\quad(\mathrm{n}=185)\end{array}$} \\
\hline & $\begin{array}{r}\text { No AE } \\
n(\%)\end{array}$ & $\begin{aligned} \geq 1 \mathrm{AE} \\
\mathrm{n}(\%)\end{aligned}$ & $\mathrm{P}$ & $\begin{array}{r}\text { No AE } \\
\text { n (\%) }\end{array}$ & $\begin{array}{r}\geq 1 \mathrm{AE} \\
\mathrm{n}(\%)\end{array}$ & $\mathrm{P}$ & $\begin{array}{r}\text { No AE } \\
\text { n (\%) }\end{array}$ & $\begin{array}{l}\geq 1 \mathrm{AE} \\
\mathrm{n}(\%)\end{array}$ & $\mathrm{F}$ \\
\hline Overall & $63(34)$ & $122(66)$ & & $44(26)$ & $125(74)$ & & $51(28)$ & $134(72)$ & \\
\hline Age at cancer diagnosis & & & 0.143 & & & 0.001 & & & 0.102 \\
\hline$<5$ year $(n=73)$ & $29(40)$ & $44(60)$ & & $28(40)$ & $42(60)$ & & $26(36)$ & $47(64)$ & \\
\hline $5-9$ years $(n=41)$ & $16(39)$ & $25(61)$ & & $9(25)$ & $27(75)$ & & $11(27)$ & $30(73)$ & \\
\hline $10-16$ years $(n=71)$ & $18(25)$ & $53(75)$ & & $7(11)$ & 56 (89) & & $14(20)$ & $57(80)$ & \\
\hline Ototoxic cancer treatment & & & 0.068 & & & 0.050 & & & $<0.001$ \\
\hline Cranial radiation $\geq 30$ Gy $(n=16)$ & $5(31)$ & $11(69)$ & & $-{ }^{\mathrm{a}}$ & $--^{a}$ & & $7(44)$ & $9(56)$ & \\
\hline Carboplatin $(n=49)$ & $21(43)$ & $28(57)$ & & $19(39)$ & $30(61)$ & & $24(49)$ & $25(51)$ & \\
\hline Cisplatin $(\mathrm{n}=67)^{\mathrm{b}}$ & $15(22)$ & $52(77)$ & & $13(19)$ & $54(81)$ & & $10(15)$ & $57(85)$ & \\
\hline Platinum and cranial radiation $\geq 30$ Gy $(n=53)$ & $22(42)$ & $31(58)$ & & $12(23)$ & $41(77)$ & & 10 (19) & $43(81)$ & \\
\hline Clinical study participation & & & 0.009 & & & $<0.001$ & & & $<0.001$ \\
\hline Officially included in a clinical study $(\mathrm{n}=93)$ & $25(27)$ & $68(73)$ & & $15(18)$ & $70(82)$ & & $23(25)$ & $70(75)$ & \\
\hline Treated according to a clinical study $(n=75)$ & $27(36)$ & $48(64)$ & & $18(26)$ & $52(74)$ & & $15(20)$ & $60(80)$ & \\
\hline Treated not according to a clinical study $(\mathrm{n}=17)$ & $11(65)$ & $6(35)$ & & $11(79)$ & $3(21)$ & & $13(76)$ & $4(24)$ & \\
\hline Hearing loss at most recent audiological testing ${ }^{c}$ & & & 0.622 & & & 0.108 & & & 0.402 \\
\hline No $(n=115)$ & $35(30)$ & $80(70)$ & & $26(25)$ & $80(75)$ & & $27(23)$ & $88(77)$ & \\
\hline Yes $(n=56)$ & $15(27)$ & $41(73)$ & & $7(13)$ & 45 (87) & & $10(18)$ & $46(82)$ & \\
\hline
\end{tabular}

Abbreviation: AE, audiological evaluation, P, P-value.

${ }^{a}$ Only 169 patients, those treated with platinum, could have had audiological monitoring during treatment because monitoring is not conducted during treatment with cranial radiation.

bIncludes 7 patients who received both cisplatin and carboplatin.

${ }^{\mathrm{c}}$ Hearing outcome was not available for 14 patients. 
TABLE 3 Frequency of audiological evaluations per patient (including only patients with at least one audiological evaluation)

\begin{tabular}{|c|c|c|c|c|c|c|c|c|c|}
\hline & \multicolumn{2}{|c|}{$\begin{array}{l}\text { Before } \\
\text { treatment }\end{array}$} & \multicolumn{2}{|c|}{ During treatment } & \multicolumn{3}{|c|}{ After treatment } & \multicolumn{2}{|c|}{$\begin{array}{l}\text { Audiological follow- } \\
\text { up period in months }\end{array}$} \\
\hline & $\begin{array}{l}\text { Median } \\
\text { (range) }\end{array}$ & $\mathrm{P}^{\mathrm{a}}$ & $\begin{array}{l}\text { Median } \\
\text { (range) }\end{array}$ & $\mathrm{P}^{\mathrm{a}}$ & $\begin{array}{c}\text { Median } \\
\text { (range) }\end{array}$ & $\begin{array}{c}\text { Std. } \\
\text { Median }^{\mathrm{b}}\end{array}$ & $\mathrm{P}^{\mathrm{c}}$ & $\begin{array}{l}\text { Median } \\
\text { (range) }\end{array}$ & $\mathrm{P}^{\mathrm{a}}$ \\
\hline Overall & $1(1-3)$ & & $3(1-17)$ & & $2(1-13)$ & 0.33 & & $29(1-112)$ & \\
\hline Age at cancer diagnosis & & 0.792 & & 0.054 & & & 0.020 & & 0.553 \\
\hline$<5$ year $(\mathrm{n}=73)$ & $1(1-3)$ & & $2(1-17)$ & & $2(1-13)$ & 0.28 & & $41(1-108)$ & \\
\hline $5-9$ years $(n=41)$ & $1(1-2)$ & & $4(1-16)$ & & $2(1-7)$ & 0.33 & & $25(1-86)$ & \\
\hline $10-16$ years $(n=71)$ & $1(1-2)$ & & $3(1-11)$ & & $2(1-11)$ & 0.42 & & $28(2-112)$ & \\
\hline Ototoxic cancer treatment & & 0.295 & & $<0.001$ & & & 0.366 & & 0.013 \\
\hline Cranial radiation $\geq 30$ Gy $(\mathrm{n}=16)$ & $1(1-1)$ & & $-{ }_{-1}^{f}$ & & $2(1-11)$ & 0.44 & & $56(30-64)$ & \\
\hline Carboplatin (n=49) & $1(1-2)$ & & $2(1-17)$ & & $2(1-4)$ & 0.28 & & $17(1-108)$ & \\
\hline Cisplatin $(\mathrm{n}=67)^{\mathrm{e}}$ & $1(1-3)$ & & $3(1-6)$ & & $2(1-13)$ & 0.33 & & $34(1-112)$ & \\
\hline Platinum and cranial radiation $\geq 30$ Gy $(n=53)$ & $1(1-2)$ & & $4(1-9)$ & & $2(1-11)$ & 0.40 & & $29(2-86)$ & \\
\hline Clinical study participation & & 0.603 & & 0.420 & & & 0.036 & & 0.834 \\
\hline Officially included in a clinical study ( $\mathrm{n}=93$ ) & $1(1-3)$ & & $3(1-17)$ & & $2(1-13)$ & 0.29 & & $29(1-112)$ & \\
\hline Treated according to a clinical study $(n=75)$ & $1(1-2)$ & & $3(1-9)$ & & $2(1-11)$ & 0.40 & & $30(1-86)$ & \\
\hline Treated not according to a clinical study ( $\mathrm{n}=17$ ) & $1(1-2)$ & & $1(1-2)$ & & $1(1-2)$ & 0.20 & & $8(2-108)$ & \\
\hline Hearing loss at most recent audiological testing & & 0.627 & & 0.062 & & & $<0.001$ & & 0.281 \\
\hline No $(n=115)$ & $1(1-2)$ & & $3(1-17)$ & & $2(1-7)$ & 0.29 & & $27(1-108)$ & \\
\hline Yes $(n=56)$ & $1(1-3)$ & & $3(1-9)$ & & $4(1-13)$ & 0.47 & & $39(4-112)$ & \\
\hline
\end{tabular}

Abbreviations: Std, Standardized; P, P-value.

${ }^{\text {ap}} \mathrm{P}$-value derived from equality-of-medians test.

${ }^{\mathrm{b}}$ Median is standardized for time between last ototoxic treatment and time of data collection. It shows the median number of audiological evaluations per year of follow-up.

${ }^{\mathrm{C}} \mathrm{P}$-value derived from standardized median using equality-of-medians test.

${ }^{\mathrm{d}}$ Includes only patients with $\geq 5$ years between last ototoxic treatment and time of study.

eIncludes 7 patients who received both cisplatin and carboplatin.

${ }^{\mathrm{f}}$ Only those treated with platinum, could have had audiological monitoring during treatment because monitoring is not conducted during treatment 
with cranial radiation. 
TABLE 4 Predictors of audiological monitoring in childhood cancer patients

\begin{tabular}{|c|c|c|c|c|c|c|c|c|}
\hline & \multicolumn{4}{|c|}{$\begin{array}{c}\text { Full audiological monitoring } \\
\text { ( } \geq 1 \text { audiological evaluation before, during, and } \\
\text { after treatment) } \\
(\mathrm{n}=78)\end{array}$} & \multicolumn{4}{|c|}{$\begin{array}{c}\text { Minimal audiological monitoring } \\
(\geq 1 \text { audiological evaluation after treatment) } \\
(\mathrm{n}=134)\end{array}$} \\
\hline & $\mathrm{n}\left(\%^{\mathrm{a}}\right)$ & $\begin{array}{l}\text { Crude OR } \\
(95 \% \text { CI }) \\
\end{array}$ & $\begin{array}{c}\text { Adjusted OR } \\
(95 \% \text { CI })\end{array}$ & $\mathrm{P}^{\mathrm{b}}$ & $\mathrm{n}\left(\%^{\mathrm{c}}\right)$ & $\begin{array}{l}\text { Crude OR } \\
(95 \% \text { CI }) \\
\end{array}$ & $\begin{array}{c}\text { Adjusted OR } \\
(95 \% \text { CI })\end{array}$ & $\mathrm{P}^{\mathrm{b}}$ \\
\hline Gender & & & & 0.404 & & & & 0.928 \\
\hline Female $(\mathrm{n}=92)$ & $38(41)$ & 1.0 & 1.0 & & $63(68)$ & 1.0 & 1.0 & \\
\hline Male (n=93) & $39(42)$ & $1.0(0.6-1.8)$ & $0.8(0.4-1.4)$ & & $71(76)$ & $1.5(0.8-2.8)$ & $1.0(0.5-2.2)$ & \\
\hline Age at cancer diagnosis & & & & 0.052 & & & & 0.824 \\
\hline$<5$ years $(n=73)$ & $24(33)$ & 1.0 & 1.0 & & $47(64)$ & 1.0 & 1.0 & \\
\hline $5-9$ years $(n=41)$ & $13(32)$ & $0.9(0.4-2.2)$ & $0.7(0.3-1.8)$ & & $30(73)$ & $1.5(0.7-3.5)$ & $1.0(0.4-2.5)$ & \\
\hline $10-16$ years $(n=71)$ & $40(56)$ & $2.6(1.3-5.2)$ & $1.9(0.9-4.1)$ & & $57(80)$ & $2.3(1.1-4.8)$ & $1.3(0.5-3.2)$ & \\
\hline Ototoxic cancer treatment & & & & 0.495 & & & & 0.031 \\
\hline Cranial radiation $\geq 30$ Gy $(n=16)$ & $7(44)$ & 1.0 & 1.0 & & $9(56)$ & 1.0 & 1.0 & \\
\hline Carboplatin (n=49) & $12(24)$ & $0.4(0.1-1.4)$ & $0.6(0.2-2.1)$ & & $25(51)$ & $0.8(0.3-2.5)$ & $0.9(0.3-3.2)$ & \\
\hline Cisplatin $(n=67)^{d}$ & $37(55)$ & $1.6(0.5-4.8)$ & $1.1(0.3-3.7)$ & & $57(85)$ & $4.4(1.3-14.6)$ & $2.5(0.7-9.1)$ & \\
\hline Platinum and cranial radiation $\geq 30$ Gy $(n=53)$ & $21(40)$ & $0.8(0.3-2.6)$ & $0.7(0.2-2.5)$ & & $43(81)$ & $3.3(1.0-11.1)$ & $1.5(0.7-3.3)$ & \\
\hline Clinical study participation & & & & 0.006 & & & & 0.010 \\
\hline Officially included in clinical study $(\mathrm{n}=93)$ & $48(52)$ & 1.0 & 1.0 & & $70(75)$ & 1.0 & 1.0 & \\
\hline Treated according to clinical study $(n=75)$ & $28(37)$ & $0.6(0.3-1.0)$ & $0.6(0.3-1.2)$ & & $60(80)$ & $1.3(0.6-2.7)$ & $1.5(0.7-3.3)$ & \\
\hline Treated not according to a clinical study $(\mathrm{n}=17)$ & $1(6)$ & $0.1(0.1-0.5)$ & $0.1(0.0-0.6)$ & & $4(24)$ & $0.1(0.1-0.3)$ & $0.2(0.1-0.8)$ & \\
\hline
\end{tabular}

Abbreviation: P, p-value; OR, odds ratio; CI, confidence interval.

aproportions of children with full audiological monitoring of the total number of children in the respective category.

${ }^{b} \mathrm{P}$-value from multivariable regression using likelihood ratio test.

'Proportions of children with minimal audiological monitoring of the total number of children in the respective category.

${ }^{\mathrm{d}}$ Includes 7 patients who received both cisplatin and carboplatin. 


\section{Supplemental}

Supplementary TABLE S1 Recommendations for audiological monitoring

\begin{tabular}{|c|c|c|c|c|c|c|}
\hline & $\begin{array}{l}\text { Before } \\
\text { treatment }\end{array}$ & During treatment & After treatment & $\begin{array}{l}\text { Minimal } \\
\text { number of } \\
\text { evaluations } \\
\text { in total }\end{array}$ & Grading scale & Type of audiological test \\
\hline \multicolumn{7}{|c|}{ Clinical study protocol $^{\mathrm{a}}$} \\
\hline $\begin{array}{l}\text { ACNS0331 for } \\
\text { Medulloblastoma }\end{array}$ & Yes & $\begin{array}{l}\text { Prior to every cycle } \\
\text { with cisplatin }\end{array}$ & $\begin{array}{l}\text { Within } 6 \text { weeks of completion of } \\
\text { chemotherapy, after } 1 \text { year, after } 3 \\
\text { years, annually after } 3 \text { years, obtain } \\
\text { at } 5 \text { years only if clinically } \\
\text { indicated }\end{array}$ & 6 & CTCAE & $\begin{array}{l}\text { Audiometry (not further } \\
\text { specified) }\end{array}$ \\
\hline $\begin{array}{l}\text { HIT-2000 for } \\
\text { Medulloblastoma/ } \\
\text { CNS PNET/ } \\
\text { Ependymoma }\end{array}$ & Yes & $\begin{array}{l}\text { With each cycle of } \\
\text { cis- or carboplatin, } \\
\text { or radiotherapy (not } \\
\text { specified whether } \\
\text { before or after) }\end{array}$ & $\begin{array}{l}\text { Once per year for the first two } \\
\text { years; following years, individually }\end{array}$ & 4 & CTCAE & Tone audiometry \\
\hline $\begin{array}{l}\text { Euramos-1 for } \\
\text { osteosarcoma }\end{array}$ & Yes & $\begin{array}{l}\text { Prior } 3^{\text {rd }} \text { and } 4^{\text {th }} \text { AP } \\
\text { cycle; } \\
\text { after last cycle of } \\
\text { chemotherapy }\end{array}$ & $\begin{array}{l}\text { Within } 4 \text { weeks after } \\
\text { chemotherapy. If no impairment } \\
\text { found it is possible to stop, but } \\
\text { audiological monitoring is } \\
\text { recommended until } 10 \text { years after } \\
\text { end of therapy. }\end{array}$ & 5 & CTCAE & $\begin{array}{l}\text { Audiometry (not further } \\
\text { specified) }\end{array}$ \\
\hline \multicolumn{7}{|c|}{ Ototoxicity monitoring protocol } \\
\hline ASHA 1994 & Yes & $\begin{array}{l}\text { Prior to every cycle } \\
\text { of platinum } \\
\text { chemotherapy }\end{array}$ & $\begin{array}{l}\text { As soon as possible after treatment, } \\
3 \text { and } 6 \text { months after platinum } \\
\text { chemotherapy }\end{array}$ & 5 & Not specified & $\begin{array}{l}\text { Pure tone audiometry including } \\
\text { high frequencies, otoscopy, } \\
\text { tympanometry, speech } \\
\text { audiometry }\end{array}$ \\
\hline AAA 2009 & Yes & $\begin{array}{l}\text { Prior to each cycle } \\
\text { of platinum } \\
\text { chemotherapy }\end{array}$ & $\begin{array}{l}\text { Few months after platinum } \\
\text { chemotherapy } \\
\text { Cranial radiation: annually 1-2 } \\
\text { years }\end{array}$ & 3 & $\begin{array}{l}\text { CTCAE, } \\
\text { Brock's } \\
\text { hearing loss } \\
\text { grades }\end{array}$ & $\begin{array}{l}\text { Baseline testing with all tests } \\
\text { needed in subsequent evaluations: } \\
\text { pure tone audiometry including } \\
\text { high frequencies, tympanometry, } \\
\text { speech audiometry, OAE testing }\end{array}$ \\
\hline
\end{tabular}




\begin{tabular}{|c|c|c|c|c|c|c|}
\hline & $\begin{array}{l}\text { Before } \\
\text { treatment }\end{array}$ & During treatment & After treatment & $\begin{array}{l}\text { Minimal } \\
\text { number of } \\
\text { evaluations } \\
\text { in total }\end{array}$ & Grading scale & Type of audiological test \\
\hline $\begin{array}{l}\text { St. Jude Children's } \\
\text { research hospital } \\
\text { ototoxicity protocol } \\
2013\end{array}$ & Yes & $\begin{array}{l}\text { Cisplatin: prior to } \\
\text { every cycle } \\
\text { Carboplatin: prior to } \\
\text { every } 2-4 \text { cycles }\end{array}$ & 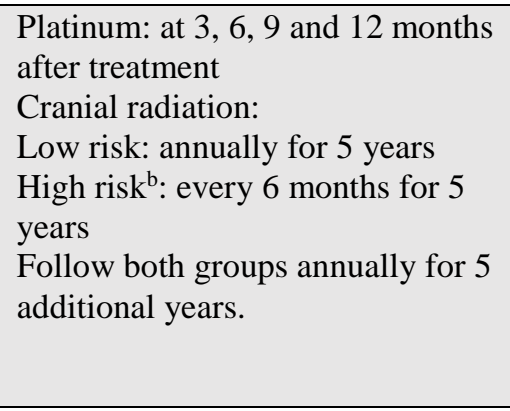 & $\begin{array}{l}\text { Platinum: } \\
11 \\
\text { Cranial } \\
\text { radiation: } \\
\text { Low risk: } \\
11 \\
\text { High risk: } \\
16\end{array}$ & Not specified & $\begin{array}{l}\text { Baseline testing: Ototoscopy, } \\
\text { tympanometry, pure tone } \\
\text { audiometry including high } \\
\text { frequencies, DPOAE testing, } \\
\text { click and tone burst ABR/ASSR } \\
\text { as indicated }\end{array}$ \\
\hline \multicolumn{7}{|c|}{ Long-term follow-up guideline } \\
\hline $\begin{array}{l}\text { Children's Oncology } \\
\text { Group } 2013\end{array}$ & NA & NA & $\begin{array}{l}\text { History for hearing difficulties, } \\
\text { tinnitus, otoscopic exam yearly. } \\
\text { Platinum: Baseline at entry into } \\
\text { follow-up. If impairment is } \\
\text { detected, test at least yearly. } \\
\text { Cranial radiation } \geq 30 \text { Gray: Yearly } \\
\text { for } 5 \text { years after treatment (by } \\
\text { patients }<10 \text { years continue yearly } \\
\text { until age } 10 \text { ), then every } 5 \text { years. } \\
\text { If impairment is detected, test at } \\
\text { least yearly. } \\
\text { If inconclusive or unevaluable, } \\
\text { consider OAE. }\end{array}$ & $\begin{array}{l}\text { NA as only } \\
\text { follow-up is } \\
\text { addressed }\end{array}$ & Not specified & $\begin{array}{l}\text { Pure tone air and bone } \\
\text { conduction, speech audiometry, } \\
\text { and tympanometry for both ears. } \\
\text { Frequency-specific auditory } \\
\text { brainstem response can be } \\
\text { performed if result is } \\
\text { inconclusive. }\end{array}$ \\
\hline $\begin{array}{l}\text { Dutch Childhood } \\
\text { Oncology Group } \\
2010\end{array}$ & NA & NA & $\begin{array}{l}\text { Cisplatin: every } 5 \text { years } \\
\text { Carboplatin: initial screen } 5 \text { years } \\
\text { after treatment, if no abnormalities } \\
\text { detected, no repeat testing is } \\
\text { required } \\
\text { Cranial radiation } \geq 30 \text { Gray: initial } \\
\text { screen } 5 \text { years afterwards, if no } \\
\text { Abnormalities detected, no repeat } \\
\text { testing required }\end{array}$ & $\begin{array}{l}\text { NA as only } \\
\text { follow-up is } \\
\text { addressed }\end{array}$ & Not specified & $\begin{array}{l}\text { Tone audiometry up to } 12.5 \mathrm{kHz} \\
\text { and tympanometry }\end{array}$ \\
\hline
\end{tabular}




\begin{tabular}{|c|c|c|c|c|c|c|}
\hline & $\begin{array}{l}\text { Before } \\
\text { treatment }\end{array}$ & During treatment & After treatment & $\begin{array}{l}\text { Minimal } \\
\text { number of } \\
\text { evaluations } \\
\text { in total }\end{array}$ & Grading scale & Type of audiological test \\
\hline $\begin{array}{l}\text { United Kingdom } \\
\text { Children`s Cancer } \\
\text { Study Group Late } \\
\text { Effects Group } \\
2011\end{array}$ & NA & NA & After completion of treatment & $\begin{array}{l}\text { NA as only } \\
\text { follow-up is } \\
\text { addressed }\end{array}$ & Not specified & $\begin{array}{l}\text { Pure tone audiogram. } \\
\text { In infants: behavioral audiometry, } \\
\text { otoacoustic emissions, or auditory } \\
\text { brainstem responses. }\end{array}$ \\
\hline
\end{tabular}

Abbreviations: AAA, American Academy of Audiology; ASHA, American Speech-Language-Hearing Association; AP-cycle, Doxorubicin-

Cisplatin cycle; ASCT, autologous stem cell transplantation; NA, not applicable; CNS, central nervous system; CTCAE, Common Terminology

Criteria of Adverse Events; DPOAE, distortion product otoacoustic emission; ABR, auditory brainstem response; ASSR, auditory steady-state response.

${ }^{a}$ We described the recommendations of the three most frequently used clinical study protocols in the study population.

${ }^{\mathrm{b}}$ Cochlear exposure $>35$ Gray. 


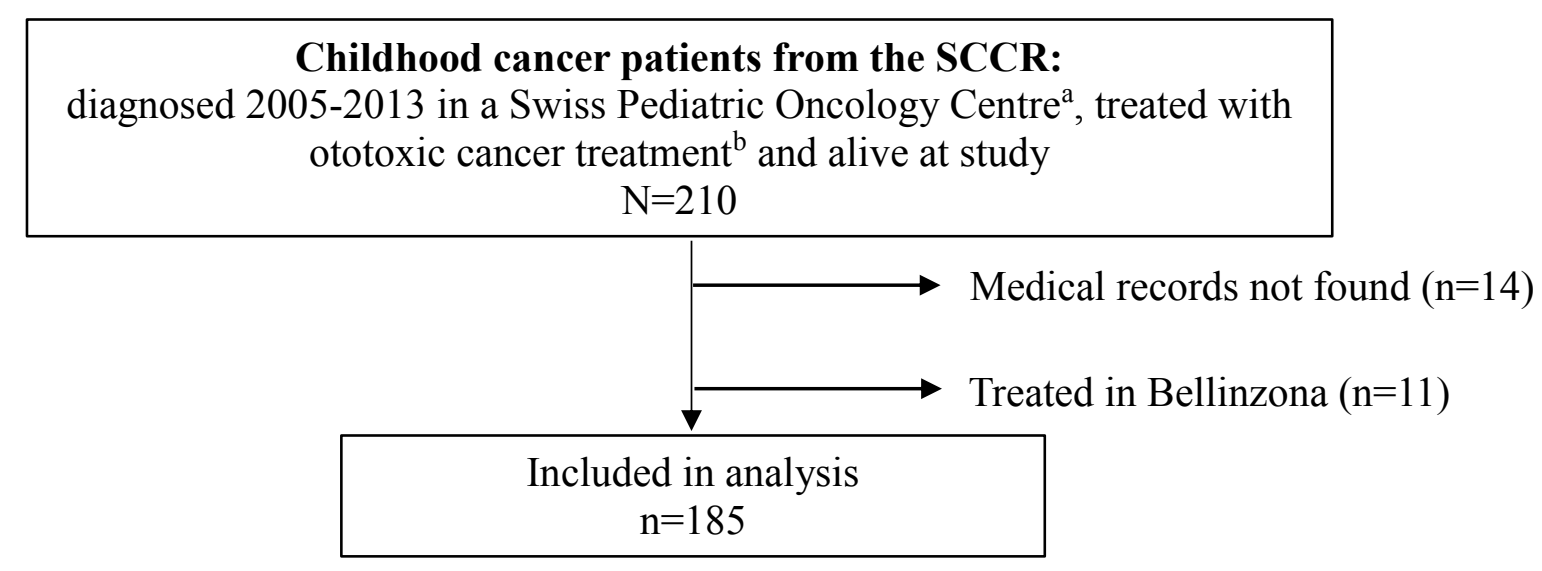

Supplementary Figure S1 Flow chart of study population.

${ }^{a}$ Including the following clinics: Kinderklinik Kantonsspital Aarau AG, UniversitätsKinderspital Basel, Universitäts-Kinderklinik Inselspital Bern, Ospedale S. Giovanni Bellinzona, Hospital des Enfants Geneve, CHUV Lausanne, Kinderklinik Kantonsspital Luzern, Ostschweizer Kinderspital St. Gallen, Universitäts-Kinderspital Zürich

${ }^{b}$ Ototoxic cancer treatment defined as platinum chemotherapy or and cranial radiation $\geq 30$ Gray. 
Supplementary TABLE S2 Type of audiological test, stratified by phase of ototoxic cancer treatment and age at diagnosis

\begin{tabular}{|c|c|c|c|c|c|c|}
\hline Type of audiological test per patient & \multicolumn{2}{|c|}{ Before treatment } & \multicolumn{2}{|c|}{ During treatment } & \multicolumn{2}{|c|}{ After treatment } \\
\hline Overall $(n=185)$ & $\mathrm{n}(\%)$ & $\begin{array}{r}\text { max number } \\
\text { of tests per } \\
\text { patient }\end{array}$ & $\mathrm{n}(\%)$ & $\begin{array}{l}\text { max number of } \\
\text { tests per patient }\end{array}$ & $\mathrm{n}(\%)$ & $\begin{array}{r}\text { max number } \\
\text { of tests per } \\
\text { patient }\end{array}$ \\
\hline Pure tone audiometry & $62(33)$ & 2 & $67(36)$ & 16 & $83(45)$ & 11 \\
\hline Extended high frequency audiometry & $32(17)$ & 2 & $44(24)$ & 11 & $43(24)$ & 9 \\
\hline Free field audiometry & $18(9)$ & 3 & $22(12)$ & 15 & $23(12)$ & 11 \\
\hline Auditory brainstem response & $8(4)$ & 1 & $5(3)$ & 2 & $7(4)$ & 2 \\
\hline OAE testing & $31(17)$ & 2 & $37(20)$ & 15 & $33(18)$ & 3 \\
\hline Speech audiometry & $0(0)$ & 0 & $2(1)$ & 2 & $12(6)$ & 5 \\
\hline Tympanometry & $10(5)$ & 1 & $18(10)$ & 4 & $28(15)$ & 5 \\
\hline
\end{tabular}

Abbreviation: OAE, otoacoustic emissions 


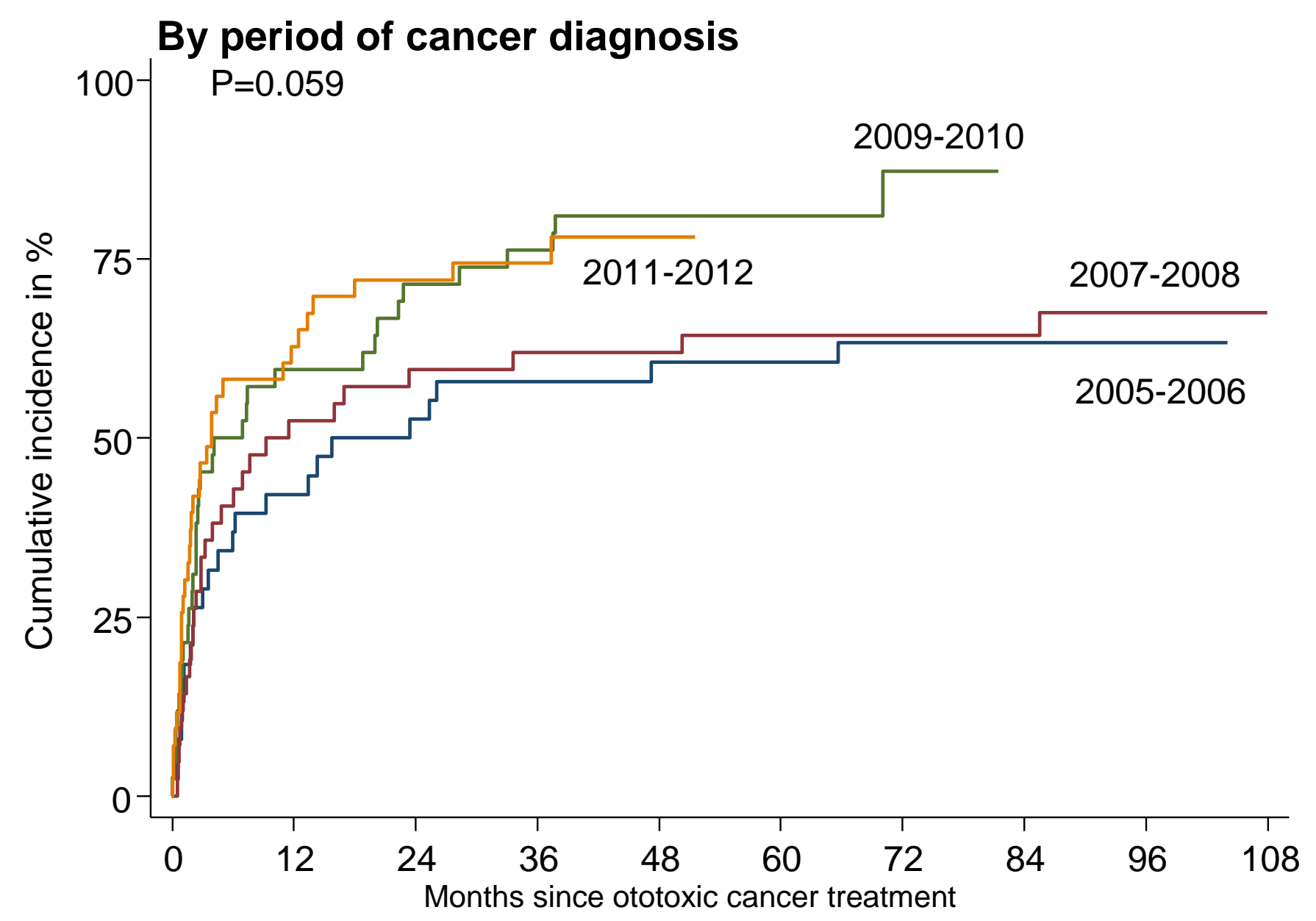

Supplementary Figure S2 Cumulative incidence of first audiological evaluation after treatment. P-value derived from log-rank test to test for equivalence of incidence curves.

We did not include patients diagnosed in 2013 as for some of those patients the period between the last ototoxic cancer treatment and the data collection was less than 12 months. 